\title{
A review on biological effects of Lamium album (white dead nettle) and its components
}

\author{
Tahere Pourmirzaee Sheikhali Kelayeh ${ }^{1}$, Mahmood Abedinzade $^{1^{*}}{ }^{\mathbb{D}}$ Ahmad Ghorbani $^{2}$ \\ ${ }^{1}$ Medical Biotechnology Research Center, Guilan University of Medical Sciences, Rasht, Iran \\ ${ }^{2}$ Pharmacological Research Center of Medicinal Plants, Mashhad University of Medical Sciences, Mashhad, Iran
}

\section{A R T I C L E IN F O}

\section{Article Type:}

Review

\section{Article History:}

Received: 27 October 2018

Accepted: 16 December 2018

\section{Keywords:}

Anticancer

Anti-inflammatory

Antioxidant

Lamium album

Nettle

\begin{abstract}
A B S T RAC T
Lamium album, commonly known as white dead nettle, is a plant in the family of Lamiaceae. This plant is distributed all over Asia, Europe, and Africa. In the traditional medicine of Asia, it has been used for the treatment of a number of diseases such as trauma, fracture, paralysis, leucorrhoea, hypertension women's pain, uterine hemorrhage, menorrhagia, vaginal and cervical inflammation. In recent years, $L$. album has been the subject of intensive experimental studies to evaluate its traditional use to reveal new biological properties. A wide range of pharmacological effects, including antimicrobial, anti-inflammatory, anticancer, and antidiabetic properties have been reported by these studies. This review presents an up-to-date overview of the current literature on the pharmacological and physiological effects of L. album. Also, phytochemical constituents responsible for the biological properties of L. album are presented and discussed.
\end{abstract}

Implication for health policy/practice/research/medical education:

This review presented the various and useful pharmacological and therapeutic effects of Lamium album against diseases such as respiratory disorders, diabetes, cancer, etc. The presented review can be used in future studies and for preparation of new drugs. Please cite this paper as: Pourmirzaee Sheikhali Kelayeh T, Abedinzade M, Ghorbani A. A review on biological effects of Lamium album (white dead nettle) and its components. J Herbmed Pharmacol. 2019;8(3):185-193. doi: 10.15171/jhp.2019.28.

\section{Introduction}

Nowadays herbal medicines have become more prominent because of their fewer costs and side effects than common chemical medicines. They are used in the preparation of ointment, syrup, herbal tea, etc. The function of these herbs is usually due to secondary metabolites (a heterogeneous group of biological active organic compounds) inside of them (1).

Lamium album has been used as an essential food in various countries of Europe, China and Japan during decades of famine (2). Nowadays it is used as a part of native foods, mainly in Mediterranean regions (2). $L$. album is widely used in traditional, folk and official medicine because of its therapeutic activities. These significant therapeutic effects are because of the production of bioactive metabolites in this herb (1). Antiseptic, astringent, and anti-inflammatory activities of this herb are specially used in the treatment of menorrhagia, leucorrhea, menstrual problems, uterine bleeding, as well as vagina and cervical inflammation (37). Thereupon, L. album is often called as the medicine of women's pain due to these therapeutic activities (5). It is also effective against chronic bronchitis and pharyngitis because of its antispasmodic and mucolytic activities (5). This herb is also used for wound healing (5).

Due to new studies on this plant in recent years, appropriate therapeutic applications of $L$. album have been identified and it can be used in future studies. For this reason, in the present review, the various compounds and the latest pharmacological effects of L. album are presented and discussed.

\section{Phytology and morphology}

The L. album herb is one of the most widespread and popular species, belonging to the Lamium genus and Lamiaceae family and commonly known as white nettle. 
Lamium genus has almost 40 species $(2,3,6,8-10)$. It is an annual and perennial plant, with 50 to $100 \mathrm{~cm}$ height, green and four-corner stems, long leaves with egg-like to kidney-like shapes, three-corners with round base, jagged edges and soft hairs. This plant has white and bilabial flowers and in the form of loops from 6 to 12 flowers placed in the upper part of the stalk (10).

The reason for folksy naming of this herb to nettle is due to its apparent similarity to Urtica dioica (Stinging nettle) plant. But unlike that, L. album hairs are not stinging $(7,10)$. Also, it is generally called white nettle because of its white flowers. As the stinging nettle is protected by its power of stinging, the protection of white nettle against livestock and leaf-eating insects occurs by its similarity with stinging nettle (10).

\section{Growing areas}

Lamium album and other species of Lamium genus are distributed all around Asia (including Iran), Europe, and Africa $(2,3,6,8)$. It grows in the ground and open areas. This plant's flowers appear in summer and are gathered in that time (11).

\section{The use of Lamium album in traditional medicine}

Lamium album (white dead nettle) is astringent and sedative. It is mainly used as a uterine tonic, for decreasing extreme menstrual flow and stopping inter-menstrual bleeding. It is also a traditional remedy for unusual vaginal secretion. This herb is sometimes used to get rid of painful periods. Its astringency helps treat diarrhea, relieve hemorrhoids and varicose veins (11).

\section{Chemical compounds}

A wide range of constituents is found in L. album, including flavonoids and phenolic acids, fatty acids, iridoids, triterpenes, saponins, polysaccharides, essential oils, tannins, phytoecdysteroids, and mucilage (4,5,12-16). Biological effects of some of these bioactive substances are presented below and summarized in Table 1.

\section{Iridoids}

The most prominent compounds existing in species of Lamium genus are iridoids which usually exist as glycosides. According to the results which have been obtained from in vivo, in vitro, and clinical studies, iridoid-rich plants have anticancer, antioxidant, antibacterial, anti-viral, anti-inflammatory, antiarthritic, immunomodulatory, neuroprotective, and wound healing activities (17).

\section{Phytoecdysteroids}

These plant steroids are analogs of insects' hormones, which are synthesized in order to defend against phytophagous insects (10). Ecologically, Lamium species are considered as an important host for some species of insects (7). They also have beneficial effects on vertebrates (10). These groups of metabolites stimulate protein synthesis and immune response, reduces the concentration of cholesterol and glucose in blood vessels and have antioxidant and antimutagenic activity and wound healing activities (10).

\section{Essential oils}

Plants of the Lamiaceae family contain high quantities of essential oils. A component of essential oil is terpenoid squalene (10). Squalene makes flowers attractive for pollinating insects and repels ants. It also has significant biological activities such as stimulation of the immune system, anti-tumor, and antibacterial properties (18). $\beta$-caryophyllene is a component of essential oil which is attributed to a number of biological activities such as anti-inflammatory, anticancer, antioxidant, antibiotic, and local anesthetizing properties (19).

Table 1. Chemical compounds in Lamium album and their biological effects

\begin{tabular}{|c|c|c|}
\hline Chemical compounds & Biological effects & References \\
\hline Iridoids & $\begin{array}{l}\text { Anticancer, antioxidant, antibacterial, anti-viral, anti-inflammatory, anti-arthritis, immune-modulatory, } \\
\text { neuro-protective, and wound healing }\end{array}$ & $(17)$ \\
\hline Phenolic compounds & $\begin{array}{l}\text { - Antioxidant, anti-inflammatory anti-microbial, free radical scavenger, analgesic, neuro-protective, hepato- } \\
\text { protective, cytotoxic. } \\
\text { - Inhibitor of the progress of tumors and cell proliferation } \\
\text { - Beneficial effects on the cardiovascular system } \\
\text { - Reduction in the risk of cancer } \\
\text { - Preservation of normal human skin fibroblasts against cellular damage caused by oxidative stress }\end{array}$ & $\begin{array}{l}(2,10,20- \\
34)\end{array}$ \\
\hline Phytoecdysteroids & $\begin{array}{l}\text { - Stimulating protein synthesis and immune response } \\
\text { - Reducing the concentration of cholesterol and glucose in blood vessels } \\
\text { - Antioxidant, antimutagenic, wound healing }\end{array}$ & $(7,10)$ \\
\hline Essential oils & $\begin{array}{l}\text { - A stimulant for immune system } \\
\text { - Anticancer, antioxidant, anti-inflammatory, antibacterial, antibiotic } \\
\text { - Local anesthetizing agents }\end{array}$ & $(10,18,19)$ \\
\hline $\begin{array}{l}\text { Other chemical } \\
\text { compounds }\end{array}$ & Fatty acids, triterpenes, saponins, polysaccharides, tannins, and mucilage & $(4,5,12-16)$ \\
\hline
\end{tabular}


Phenolic compounds

Phenolic compounds are one of the most important groups of phytochemicals in some traditional herbs (20) and play important roles against various diseases, including cardiovascular diseases (21), tumors (22), and diseases with the uncontrolled production of free radicals (23). Also, studies have shown that phenolic compounds have antioxidant and anti-inflammatory activities and inhibit the progress of tumors and cell proliferation $(24,25)$. Polyphenolic compounds behave as free radical scavengers and anti-lipid peroxidation. They protect collagen from disintegration by superoxide anion radicals (26).

Verbascoside (acteoside), isoverbascoside, and lamalboside are three phenylethanoid glycosides which are phenolic compounds detected in the aerial parts of L. album $(2,10)$. Verbascoside has various properties such as free radical scavenging, antioxidant, analgesic, neuroprotective, hepatoprotective, cytotoxic, antiinflammatory and anti-microbial activities. They also have beneficial effects on the cardiovascular system. Most of these activities are also attributed to isoverbascoside (27-31).

High quantities of flavonoids in forms of glycosides, aglycones, and phenolic acids have been found in methanol and ethyl acetate extracts derived from the flowers of L. album (5). Absorption of the flavonoids is associated with a reduction in the risk of cancer (32). In some cases, absorption of flavonoids is associated with preservation of normal human skin fibroblasts (HSFs) against cellular damage caused by oxidative stress (33). The most investigated flavonoid is quercetin, which has inhibitory effects on cell growth. This effect is probably due to the ability of quercetin to interfere with enzymatic processes regulating cell proliferation (34).

\section{Pharmacological effects of Lamium album}

Antiviral and antimicrobial activities

Hepatitis $C$ virus is the main reason of hepatic disorders such as cirrhosis of the liver and cancer in the United States. There is no vaccine against this virus and its usual treatment relies on the injection of interferon alone or in combination with ribavirin (35). Interferon-based treatment in many patients is along with side effects such as depression, mental illness and severe fatigue (35). Therefore, researchers investigated medicinal herbs in order to found a new therapeutic approach with less side effects. In this regard, Zhang et al for the first time identified antiviral activities of iridoids against hepatitis C. They identified antiviral iridoids isomers, lamiridosin A and B, by researching on an aqueous extract of L. album flowering tip. They observed that these compounds inhibited the entry of $\mathrm{HCV}$ virus $\left(\mathrm{IC}_{50}=2.31 \mu \mathrm{M}\right)$. Lamiridosin A and B were not found in the methanol extract of $L$. album, but they were found specifically in the prepared aqueous extract of this herb (35). Zhang et al conducted this study in vitro and achieved positive results from the antiviral activity of this herb. However, the antiviral activity of the iridoids should be specifically investigated to identify the molecular mechanisms.

On the other hand, herpes simplex virus type 1 and type 2 are common human pathogens $(36,37)$. The most commonly used medicines in order to treat the infection of this virus are acyclovir, its derivatives, and cidofovir (38). These drugs have been used for more than two decades (39). However, continuous treatment with these medicines leads to the formation of resistant strains (39). Therefore, Todorov et al investigated the effect of L. album extract on the proliferation and toxicity of herpes simplex virus type 1 and 2 . They observed that chloroform extract of this herb blocks the proliferation of these viruses in Madin-Darby bovine kidney line without any considerable cytotoxicity effect. It also exhibited a strong antiviral effect (40).

In 2011, Chipeva et al examined antimicrobial activities of 18 different extracts of L. album. The extracts were obtained from leaves and flowers of mature plants. All of the extracts exhibited antibacterial activities and only the aqueous extract had antifungal activity (9). In general, with the results obtained from these studies, it can be said that L. album is an appropriate source of natural antiviral materials for use in medicines. But still, further research is needed to identify the factors responsible for the antiviral activity in the extracts and their mechanism of action.

\section{Antioxidant activity}

Oxygen free radicals are involved in the pathophysiology of many diseases such as inflammation and cancer (10). Phenolic acids, polyphenols, and flavonoids are antioxidant compounds that trap free radicals and inhibit oxidative mechanisms leading to the development of degenerative diseases (41). The high antioxidant potential of Lamium's flowers can extend therapeutic uses of this plant to prevent neoplastic (cancerous) and degenerative diseases in various organs such as genital and urinary system which are one of the main goals of the medicines (42). In other words, large quantities of phenolic compounds such as flavonoids in Lamium's flowers are a sign of the adaptive approach of this herb to protect its genital organs (42). A possible relationship between antioxidant activity and phenolic compounds in the extract of this plant was reported by Trouillas et al. In 2003, they evaluated the biological properties of the aqueous extract of 16 plants (including L. album) in order to investigate their inhibitory effects on hydroxyl, superoxide, and 1, 1-diphenyl-2-picrylhydrazyl (DPPH) radicals. Some of these extracts (including $L$. album extract) were good antioxidants compared to tow reference molecules, quercetin and vitamin E (20). On the other hand, Matkowski and Piotrowska in 2006, reported anti-oxidant and free radical scavenging properties for $L$. album (43). In 2011, Valyova et al investigated the total amount of phenol content of L. album extracts in vitro and 
in vivo. As mentioned above, there is a direct correlation between phenolic compounds and antioxidant activity. In this study, the highest phenolic content and antioxidant ability were identified in ethanol and methanol extracts obtained from the plants. In general, the difference in the antioxidant properties of herbs is related to the existence of various secondary metabolites and different methods of extraction (8).

Pereira in 2013 induced chemical stress in HepG2 cells (human hepatoblastoma cells) by using potassium dichromate (DK). Oxidative stress causes the production of reactive oxygen species (ROS), but in this study, it was observed that $50 \mu \mathrm{g} / \mathrm{mL}$ of $L$. album extract reduced the production of ROS. On the other hand, the polyphenol compounds that were prepared separately from the extracts were also investigated and it was observed that they had a beneficial role in cytoprotective and antioxidant properties of this plant. In other words, the high ability of purified ethanolic extracts to neutralize ROS produced during oxidative stress conditions in HepG2 cells is related to the phenolic compounds present in these extracts (44).

Bubueanu et al in 2013, investigated the antioxidant effect of L. album botanolic extract and in order to prove the relationship between the chemical composition and the antioxidant potential of the extracts, they started quantitative determination of phenolic compounds. The results exhibited strong anti-oxidant activity of the extract. Butanol extracts also had free radical scavenging and inhibitory activities (41). In summary, the antioxidant activity of all the studied extracts was probably due to the presence of phenolic compounds in them. But still more researches are needed to study other compounds that may have a higher antioxidant effect than phenolic compounds.

\section{Cytoprotective activity}

Different $L$. album extracts with all mentioned positive effects must be evaluated in terms of toxicity on cells. Paduch et al investigated the effect of heptane, ethyl acetate, and methanol extracts of L. album on cellular toxicity and the ability to stimulate the growth of HSFs in vitro. In this study, viability and proliferation activity of normal HSFs (with $2 \times 10^{4}$ cells per $\mathrm{mL}$ density) after 72 hours of incubation with different concentrations of each 3 extract were investigated in vitro. A considerable cytotoxicity was observed in ethyl acetate and methanol extracts at concentrations greater than $125 \mu \mathrm{g} / \mathrm{mL}$. But when the cells were incubated with heptane extracts, they showed a relatively high viability rate (more than $60 \%$ ). Based on what was observed, the methanol and ethyl acetate extracts contained various amounts of free phenolic acids, flavonoids, triterpenes and iridoids but in heptane extract, only triterpenes were found. As a result, it has been assumed that triterpenes can play a role in wound healing. It has also been exhibited that heptane extracts, even in high concentrations, is not toxic to HSFs. Thus, triterpenes can specifically exert stimulant effects on the proliferative ability of HSF cells and maintain its relatively high viability. It should be noted that we cannot ignore the presence of other bioactive substances in L. album because they may also play a role in wound healing (5).

On the other hand, Paduch et al in 2008 also studied and evaluated cytostatic, cytotoxic, and free radical scavenging activities of $L$. album ethyl acetate and methanol extracts on normal HSF. Their goal was to measure the possible benefits of extracts in newer wound healing treatments. The studied herbal extracts did not exhibit toxic influences on HSF cells (12). Secondary metabolites, including flavonoid quercetin and triterpene ursolic acid, inhibit the proliferation of tumor and normal human cells by blocking the progression of the cell cycle at the G1 stage and causes apoptosis. Therefore, any antiproliferative effect can be attributed to these secondary metabolites existing in the extracts (45-47). Ethyl acetate extracts limited HSF cell proliferation more efficiently than methanol extract because they contained higher concentrations of ursolic acid. Additionally, the antiproliferative activity of the examined extracts may be the result of the stimulation in the production of ROS within the mitochondria (12). Plants produce different antioxidants and they prevent themselves from damage caused by ROS. Phenolic compounds are the most active antioxidants, among them, flavonoids are the most important group (48). The antioxidant activity of phenolic compounds generally relies on their oxidative properties (49). In the tests conducted in this study, caffeic acid and vanillic acid were found in methanol extracts and free radical scavenging activity was observed in this extract. But these phenols were not identified in the ethyl acetate extract and no free radical reduction was observed. As a result of this study, L. album methanol extract was nontoxic and also had antioxidative activity (12).

\section{Anticancer activity}

Cancer prevalence is increasing worldwide and researchers are looking for new treatments that have no complications which most of the current methods have. These include research on medicinal herbs. In 2011, Moskova-Doumanova et al in a study investigated cytotoxicity effects of methanol and chloroform extracts and their combination at various concentrations on cell viability, adhesive properties and cell cycle of the human lung cancer cell line $\mathrm{A}_{549^{\circ}}$. Cells were treated with extracts for 24 or 48 hours. Methanol and chloroform extracts had cytotoxic effects on these cancerous cells. It also reduced adhesive properties of cells, which this effect was stronger in incubating extracts obtained from plants. After 48 hours of incubation, the methanol and chloroform extracts caused cell survival in G2 stage and the combination of both extracts caused apoptosis. Also, a reduction in viability and adhesive properties of cells was observed. This study suggested that the chloroform and methanol extracts of this plant have potent anticancer effects. The precise 
mechanism actions of the extracts and their combination were not determined in this study (4). Also TopouzovaHristova et al in 2012, investigated the anticancer effect of methanol and chloroform extracts of L. album plant and their combination in final concentrations of $2.5 \mathrm{mg} /$ $\mathrm{mL}$ for 2-24 hours on two cell lines: human lung cancer cells (human non-small cell carcinoma, $\mathrm{A}_{549}$ cell line) and diploid cells derived from normal human embryonic lung (P) in vitro. Observations indicated no changes in the morphology of non-cancerous fetal $\mathrm{P}$ cells after treatment with extracts. However, the number of $\mathrm{A}_{549}$ cancerous cells was reduced after treatment with the combined extract. Also, in some of these cells, morphological changes such as segmentation of the nucleus, reduction of cytoplasmic volume (probably due to dehydration), cellular junction defect and disorders in cellular single layer were observed. As a result, investigated extracts have a strong anti-tumor effect and can inhibit the growth of tumor cells. This effect was not observed during treatment of normal embryonic cells, indicating the selective action of some herbal compounds (50).

In 2015, Veleva et al used human cancer cell line $\mathrm{A}_{549}$ and normal epithelial cells of kidney Madin-Darby canine kidney cells II to evaluate the anticancer effect of L. album extracts. Chloroform and methanol extracts obtained from herbs grown in vitro and in vivo had different effects on cancerous and non-cancerous cells. In herbs grown in vitro, phenolic acids and flavonoids have been significantly less accumulated. A reduction in the number of $\mathrm{A}_{549}$ cells with destroyed intercellular junctions and damaged cytoplasm was the most notable change in cancerous cells incubated with chloroform extracts. These chloroform extracts of herbs had a strong anti-cancer effect. In both cell types, the methanol extract did not affect the permeability of the membrane, while chloroform extract greatly affected it. The extracts showed a stronger effect on inhibition of cell adhesion in vitro compared to in vivo experiment (51). In studies, only the anticancer properties of this plant have been mentioned and finding a molecular composition with this effect requires more research. However, the compounds with antioxidant activity, especially phenolic compounds, also have anticancer activity and in other words, they can inhibit cell proliferation and tumor progression.

\section{Anti-inflammatory activity}

The human cornea, the outer translucent area of the eye, is continuously exposed to the exterior environment $(52,53)$. Continuous exposure of the corneal epithelium against stress factors such as mechanical damages, toxins and chemical agents and ROS adversely influences the eye function and even lead to the reduction of vision (53). Antioxidants have this capability to prevent eye damage (54). A study evaluated antioxidant, anti-inflammatory and cytotoxic effects of heptane, ethyl acetate and ethanol extracts of L. album on cultivated epithelial cells of human cornea (10.014pRSV-T cell line). The most ROS scavenging effect was observed in ethanol extract. Heptane extract of this herb did not show this effect (54). Previous studies have shown that the methanol extract of L. album has antioxidant and ROS scavenging properties (43). This activity of this extract is probably due to the presence of flavonoids and polyphenol compounds existing in the extract. The antioxidant activity of this category of secondary metabolites has been proved (20). The heptane extract does not contain these compounds, and this could be a possible explanation for the lack of ROS scavenging effect of heptane extracts. Ethanol extract and ethyl acetate extract (with a lower grade) showed DPPH radical reduction effects (54).

Ocular inflammation is associated with the high level expression of pro-inflammatory cytokines (TNF- $\alpha$, IL-6, IL-18) and anti-inflammatory cytokines such as IL-10 are not altered or reduced. This study revealed that L. album extract can reduce the production of pro-inflammatory cytokines by corneal epithelial cells. L. album extracts have an immunomodulatory activity which can be used to maintain eye health, and this activity is applied by changing the anti-inflammatory cytokine levels (54). Czerwinska et al did a study to compare the potential anti-inflammatory effects of ethanol extracts from flowers and aerial parts of L. album, using human neutrophils. Neutrophils are white blood cells that play a role in inflammatory responses. They form the first defense line against pathogens through the production of oxidative burst and the secretion of other antimicrobials (55). Both extracts (from flowers and aerial parts) at concentrations of 25 and $100 \mu \mathrm{g} /$ $\mathrm{mL}$ significantly inhibited the production of ROS and secretion of myeloperoxidase and interleukin-8 (IL-8). But these extracts did not inhibit the secretion of TNF- $\alpha$ cytokine, except extracts obtained from flowers which inhibited the secretion at its maximum concentration (100 $\mu \mathrm{g} / \mathrm{mL}$ ) (56). Phenylpropanoid, like lamiuside A, have anti-inflammatory activity besides the antioxidant properties associated with ROS scavenging and also is effective in wound healing process (57).

In 2003, Trouillas et al examined the antioxidant activity of 16 different herbs (including L. album), simultaneously with measuring the anti-inflammatory activities of extracts by examining the inhibition of lipoxygenase activity. It was found that the anti-inflammatory activities of these extracts were due to the strong inhibitory effects of their phenolic compounds on the arachidonic acid metabolism through the lipoxygenase pathway (20). The results obtained from all of these studies supported the traditional use of the L. album in the treatment of inflammatory disease and introduced this herb as a potential source of natural anti-inflammatory compounds such as phenylpropanoids (56).

Antidiabetic activity

Diabetes mellitus is the most common endocrine disorder 
worldwide, increasing blood glucose levels (58). This is due to the insulin production disorder, resistance to it, or both. Mohseni Mehran et al in 2015, conducted a study to investigate the effects of hydroalcoholic extract of L. album and Urtica dioica on glucose, lipids and serum hepatic enzyme levels in streptozotocin-induced diabetic rats. They observed hydroalcoholic extract of these two herbs caused a significant reduction of serum glucose level in diabetic rats. Also, compared to the diabetic control group, the extract of L. album significantly reduced cholesterol, alkaline phosphatase, aspartate transaminase, and alanine transaminase. Serum triglyceride levels in diabetic rats treated with Urtica dioica decreased more than the ones in the rats treated with L. album. But generally, they reached this conclusion that the injection of both of the herbal extracts to diabetic rats could have reduced effects on serum glucose, cholesterol, and hepatic enzyme levels. However, Urtica dioica can be more effective in the betterment of serum TG compared to L. album. The beneficial effects of these two herbs on serum liver enzymes can be due to the antioxidant and cytoprotective properties of these extracts (58). Also, in another study by the same group, the effects of hydroalcoholic extract of L. album and $U$. dioica on serum sugar levels and lipid profile in diabetic rats were investigated. According to the results, both extracts caused a significant reduction in the serum sugar level in diabetic rats compared to the control group (healthy). Also, serum cholesterol, LDL and LDL/ HDL ratio in these diabetic rats treated with both extracts decreased and serum HDL levels increased in this group (59). Khanaki et al in 2017, also investigated the effect of L. album extract on the serum level of insulin-like growth factor-1 (IGF-1) on a diabetic rat model (inducted with streptozotocin) in their study (60). Streptozotocin in rats leads to diabetes mellitus type 1 (61) and insulin, on the other hand, increases the production of IGF-1 in the liver $(62,63)$. But because insulin does not produce in diabetes type 1 and its production is low, the level of this factor has decreased in the serum of diabetic rats and in this study, the extracts of this herb could increase the level of this factor in the serum of diabetic rats treated with this extract. This finding can support the positive effects of L. album extracts on diabetes (60). In another study by Khanaki et al. In 2017, they studied the effects of this herb on production of mitochondrial ROS in blood neutrophils in diabetic rats. They observed that L. album could not reduce the mitochondrial ROS in neutrophils in a dose used in this study (100 mg/kg) (64).

Effect of Lamium album on the smooth muscle of trachea Arefani et al in 2018 investigated the effect of L. album extract on the contraction of tracheal smooth muscle, induced by potassium chloride. In this study, they observed that the L. album extract had a significant effect on the trachea muscle relaxation at the concentration of 5 $\mathrm{mg} / \mathrm{mL}$ and, in other words, reduced its contraction. As noted, L. album contains various phenolic compounds $(2,41,65)$. Also, the relaxant effects of phenolic compounds such as quercetin, rutine, and derivatives of caffeic acid on segregated human bronchial tubes have been reported $(66,67)$ and concluded that L. album relaxing effect might be due to its phenolic compounds. Therefore, considering the observed effect, L. album can be an approach for controlling patients with obstructive pulmonary disease and asthma (68).

In a research conducted by Roman et al in 2016, during the 17-day period of darkness and inactivity, an akinetic stress was induced in Wistar rats. The induction of the stress led to the increased triglycerides, cholesterol and hepatic transaminase and decreased serum creatinine (69). Also, long-term akinetic stress induced the formation of ROS, hydrogen peroxide, and other active species of free radicals, causing peroxidation of lipids, especially on the surface of cell membranes, which have destructive effects on all tissues (70). By injecting L. album extract to stressed rats, levels of triglyceride and hepatic transaminases increased, cholesterol decreased, and serum creatinine levels increased (69). As mentioned in effect of L. album on diabetes mellitus section, in a study conducted by Mohseni Mehran et al in 2015 on diabetic rats, the levels of triglyceride and hepatic transaminases in diabetic rats decreased after treatment with the L. album extract. But, in a study on akinetic stress-induced rats, the levels of triglyceride and hepatic transaminases increased after injection of the extract of this herb. This difference, therefore, may be due to different general conditions of research or different conditions of the disease (diabetes and stress). More studies are required for a more accurate diagnosis on this difference.

\section{Conclusion}

Lamium album herb is used widely in traditional medicine for the treatment of many diseases and disorders. Hence, many medicinal chemistry researchers became interested in investigating and recognizing the compounds existing in this herb. As a result of these studies, the existence of a variety of secondary metabolites including iridoids, phenolic compounds, essential oils, flavonoids, terpenes, phytoecdysteroids, etc has been identified. The obtained data were the basis of other studies to investigate various medicinal effects of this herb, including, antioxidant, anti-inflammatory, antiviral, antibacterial and anticancer effects. In this review article, a summary of the last findings obtained from pharmacological and biochemical studies on different extracts of this herb was gathered to make possible designing of clinical studies. Also, future works are needed to understand the exact molecular mechanisms responsible for L. album effects, its possible toxicity, and drug-drug interactions.

\section{Authors' contributions}

TP, SK and MA wrote the first draft of the paper. MA and 
AG did critical revision. All authors read and approved final version of the manuscript.

\section{Conflict of interests}

All authors state that there is no conflict of interest in the present study.

\section{Ethical considerations}

This work was done according to ethical guideline of an ethic committee of Guilan University of Medical Sciences. Ethical code: IR.GUMS.RED.1395.222.

\section{Funding/Support}

All authors are grateful of vice chancellor of research deputy of Guilan University of Medical Scienecs for financial support (Grant number: 95071705).

\section{References}

1. Veleva R, Moskova-Doumanova V, Doumanov J, KapchinaToteva V, Topouzova-Hristova T. Comparative analysis of biological activity of extracts from cultivated and wild plants Lamium album L. Sci Technol. 2014;4(1):122-6.

2. Pereira OR, Domingues MRM, Silva AMS, Cardoso SM. Phenolic constituents of Lamium album: Focus on isoscutellarein derivatives. Food Res Int. 2012;48(1):330-5. doi: $\quad$ 10.1016/j.foodres.2012.04.009.

3. Morteza-Semnani K, Saeedi M, Akbarzadeh M. Chemical composition of the essential oil of the flowering aerial parts of Lamium album L. Journal of Essential Oil Bearing Plants. 2016;19(3):773-7. doi: 10.1080/0972060X.2016.1168321.

4. Moskova-Doumanova V, Miteva G, Dimitrova M, Topouzova-Hristova T, Kapchina V. Methanol and Chloroform Extracts from Lamium Album L. affect cell properties of A549 cancer lung cell line. Biotechnol Biotechnol Equip. 2012;26(Suppl 1):120-5. doi: 10.5504/50YRTIMB.2011.0022.

5. Paduch R, Wojciak-Kosior M, Matysik G. Investigation of biological activity of Lamii albi flos extracts. J Ethnopharmacol. 2007;110(1):69-75. doi: 10.1016/j. jep.2006.09.004.

6. Akkol EK, Yalcin FN, Kaya D, Calis I, Yesilada E, Ersoz T. In vivo anti-inflammatory and antinociceptive actions of some Lamium species. J Ethnopharmacol. 2008;118(1):16672. doi: 10.1016/j.jep.2008.04.001.

7. Yalcin FN, Kaya D. Ethnobotany, pharmacology and phytochemistry of the genus Lamium (Lamiaceae). Fabad J Pharm Sci. 2006;31(1):43-52.

8. Valyova MS, Dimitrova MA, Ganeva YA, Kapchina-Toteva VM, Yordanova ZP. Evaluation of antioxidant and free radical scavenging potential of Lamium album $\mathrm{L}$. growing in Bulgaria. J Pharm Res. 2011;4(4):945-7.

9. Chipeva VA, Petrova DC, Geneva ME, Dimitrova MA, Moncheva PA, Kapchina-Toteva VM. Antimicrobial activity of extracts from in vivo and in vitro propagated Lamium album L. plants. Afr J Tradit Complement Altern Med. 2013;10(6):559-62.

10. Yordanova ZP, Zhiponova MK, Iakimova ET, Dimitrova MA, Kapchina-Toteva VM. Revealing the reviving secret of the white dead nettle (Lamium album L.). Phytochem Rev.
2014;13(2):375-89. doi: 10.1007/s11101-014-9356-2.

11. Chevallier A. Encyclopedia of herbal medicine. 3rd ed. New York: Penguin; 2016:226.

12. Paduch R, Matysik G, Wojciak-Kosior M, KandeferSzerszen M, Skalska-Kaminska A, Nowak-Kryska M, et al. Lamium album extracts express free radical scavenging and cytotoxic activities. Pol J Environ Stud. 2008;17(4):569-80.

13. Alipieva KI, Taskova RM, Evstatieva LN, Handjieva NV, Popov SS. Benzoxazinoids and iridoid glucosides from four Lamium species. Phytochemistry. 2003;64(8):1413-7.

14. Savchenko T, Blackford M, Sarker SD, Dinan L. Phytoecdysteroids from Lamium spp: identification and distribution within plants. Biochem Syst Ecol. 2001;29(9):891-900.

15. Chudnicka A, Matysik G. Research of enzymatic activities of fresh juice and water infusions from dry herbs. J Ethnopharmacol. 2005;99(2):281-6. doi: 10.1016/j. jep.2005.02.016.

16. Alipieva K, Kokubun T, Taskova R, Evstatieva L, Handjieva N. LC-ESI-MS analysis of iridoid glucosides in Lamium species. Biochem Syst Ecol. 2007;35(1):17-22. doi: 10.1016/j. bse.2006.07.004.

17. Ghule B, Palve S, Rathi L, Yeole P. Validated HPTLC method for simultaneous determination of shanzhiside methyl ester and barlerin in Barleria prionitis. J Planar Chromat. 2012;25(5):426-32. doi: 10.1556/JPC.25.2012.5.7.

18. Dutton A, Mattiacci L, Amado R, Dorn S. A novel function of the triterpene squalene in a tritrophic system. J Chem Ecol. 2002;28(1):103-16.

19. Legault J, Pichette A. Potentiating effect of betacaryophyllene on anticancer activity of alpha-humulene, isocaryophyllene and paclitaxel. J Pharm Pharmacol. 2007;59(12):1643-7. doi: 10.1211/jpp.59.12.0005.

20. Trouillas P, Calliste CA, Allais DP, Simon A, Marfak A, Delage C, et al. Antioxidant, anti-inflammatory and antiproliferative properties of sixteen water plant extracts used in the Limousin countryside as herbal teas. Food Chem. 2003;80(3):399-407. doi: 10.1016/S0308-8146(02)00282-0.

21. Visioli F, Galli C. Natural antioxidants and prevention of coronary heart disease: The potential role of olive oil and its minor constituents. Nutr Metab Cardiovasc Dis. 1995;5(4):306-314.

22. Visioli F, Bellomo G, Galli C. Free radical-scavenging properties of olive oil polyphenols. Biochem Biophys Res Commun. 1998;247(1):60-4. doi: 10.1006/bbrc.1998.8735.

23. Duthie GG, Wahle KW, James WP. Oxidants, antioxidants and cardiovascular disease. Nutr Res Rev. 1989;2(1):51-62. doi: 10.1079/nrr19890007.

24. Huang MT, Lou YR, Ma W, Newmark HL, Reuhl KR, Conney AH. Inhibitory effects of dietary curcumin on forestomach, duodenal, and colon carcinogenesis in mice. Cancer Res. 1994;54(22):5841-7.

25. Simon A, Allais DP, Duroux JL, Basly JP, Durand-Fontanier S, Delage C. Inhibitory effect of curcuminoids on MCF7 cell proliferation and structure-activity relationships. Cancer Lett. 1998;129(1):111-6.

26. Chen JH, Ho CT. Antioxidant activities of caffeic acid and its related hydroxycinnamic acid compounds. J Agric Food Chem. 1997;45(7):2374-8. doi: 10.1021/jf970055t.

27. Fu G, Pang H, Wong YH. Naturally occurring 
phenylethanoid glycosides: potential leads for new therapeutics. Curr Med Chem. 2008;15(25):2592-613.

28. Isacchi B, Iacopi R, Bergonzi MC, Ghelardini C, Galeotti N, Norcini M, et al. Antihyperalgesic activity of verbascoside in two models of neuropathic pain. J Pharm Pharmacol. 2011;63(4):594-601. doi: 10.1111/j.20427158.2011.01264.x.

29. Korkina LG. Phenylpropanoids as naturally occurring antioxidants: from plant defense to human health. Cell Mol Biol (Noisy-le-grand). 2007;53(1):15-25.

30. Kostyuk VA, Potapovich AI, Suhan TO, de Luca C, Korkina LG. Antioxidant and signal modulation properties of plant polyphenols in controlling vascular inflammation. Eur J Pharmacol. 2011;658(2-3):248-56. doi: 10.1016/j. ejphar.2011.02.022.

31. Morikawa T, Pan Y, Ninomiya K, Imura K, Matsuda H, Yoshikawa M, et al. Acylated phenylethanoid oligoglycosides with hepatoprotective activity from the desert plant Cistanche tubulosa. Bioorg Med Chem. 2010;18(5):1882-90. doi: $10.1016 /$ j.bmc.2010.01.047.

32. O’Prey J, Brown J, Fleming J, Harrison PR. Effects of dietary flavonoids on major signal transduction pathways in human epithelial cells. Biochem Pharmacol. 2003;66(11):2075-88.

33. Spencer JP, Abd-el-Mohsen MM, Rice-Evans C. Cellular uptake and metabolism of flavonoids and their metabolites: implications for their bioactivity. Arch Biochem Biophys. 2004;423(1):148-61.

34. Lagarrigue S, Chaumontet C, Heberden C, Martel P, Gaillard-Sanchez I. Suppression of oncogene-induced transformation by quercetin and retinoic acid in rat liver epithelial cells. Cell Mol Biol Res. 1995;41(6):551-60.

35. Zhang H, Rothwangl K, Mesecar AD, Sabahi A, Rong L, Fong HH. Lamiridosins, hepatitis C virus entry inhibitors from Lamium album. J Nat Prod. 2009;72(12):2158-62. doi: 10.1021/np900549e.

36. Khan MT, Ather A, Thompson KD, Gambari R. Extracts and molecules from medicinal plants against herpes simplex viruses. Antiviral Res. 2005;67(2):107-19. doi: 10.1016/j.antiviral.2005.05.002.

37. Xu F, Sternberg MR, Kottiri BJ, McQuillan GM, Lee FK, Nahmias AJ, et al. Trends in herpes simplex virus type 1 and type 2 seroprevalence in the United States. JAMA. 2006;296(8):964-73. doi: 10.1001/jama.296.8.964.

38. Elion GB. Acyclovir: discovery, mechanism of action, and selectivity. J Med Virol. 1993; Suppl 1:2-6.

39. Bacon TH, Levin MJ, Leary JJ, Sarisky RT, Sutton D. Herpes simplex virus resistance to acyclovir and penciclovir after two decades of antiviral therapy. Clin Microbiol Rev. 2003;16(1):114-28.

40. Todorov D, Dimitrova M, Shishkova K, Yordanova ZP, Kapachina-Toteva V, Shishkov S. Comparative antiherpes effects of the chloroform in vitro and in vivo extracts, derived from Lamium album L. Bulg J Agric Sci. 2013;19(2):190-3.

41. Bubueanu C, Gheorghe C, Pirvu L, Bubueanu G. Antioxidant activity of butanolic extracts of Romanian native species -Lamium album and Lamium purpureum. Rom Biotechnol Lett. 2013;18(6): 8855-62.

42. Matkowski A. Plant phenolic metabolites as antioxidants and mutagenesisinhibitors. Cell Biol Instrum. 2006;376:129-48.
43. Matkowski A, Piotrowska M. Antioxidant and free radical scavenging activities of some medicinal plants from the Lamiaceae. Fitoterapia. 2006;77(5):346-53. doi: 10.1016/j. fitote.2006.04.004.

44. Pereira OR, Macias RIR, Perez MJ, Marin JJG, Cardoso SM. Protective effects of phenolic constituents from Cytisus multiflorus, Lamium album L. and Thymus citriodorus on liver cells. J Funct Foods. 2013;5(3):1170-9. doi: 10.1016/j. jff.2013.03.014.

45. Hsu YL, Kuo PL, Lin CC. Proliferative inhibition, cell-cycle dysregulation, and induction of apoptosis by ursolic acid in human non-small cell lung cancer A549 cells. Life Sci. 2004;75(19):2303-16. doi: 10.1016/j.lfs.2004.04.027.

46. Jakubowicz-Gil J, Paduch R, Piersiak T, Glowniak K, Gawron A, Kandefer-Szerszen M. The effect of quercetin on pro-apoptotic activity of cisplatin in HeLa cells. Biochem Pharmacol. 2005;69(9):1343-50. doi: 10.1016/j. bcp.2005.01.022.

47. Ma CM, Cai SQ, Cui JR, Wang RQ, Tu PF, Hattori M, et al. The cytotoxic activity of ursolic acid derivatives. Eur J Med Chem. 2005;40(6):582-9. doi: 10.1016/j. ejmech.2005.01.001.

48. Di Mambro VM, Fonseca MJ. Assays of physical stability and antioxidant activity of a topical formulation added with different plant extracts. J Pharm Biomed Anal. 2005;37(2):287-95. doi: 10.1016/j.jpba.2004.10.030.

49. Sterbova D, Matejicek D, Vlcek J, Kuban V. Combined microwave-assisted isolation and solid-phase purification procedures prior to the chromatographic determination of phenolic compounds in plant materials. Anal Chim Acta. 2004;513(2):435-44. doi: 10.1016/j.aca.2004.03.031.

50. Topouzova-Hristova T, Moskova-Doumanova V, Keremidarska M, Doumanov J, Miteva G, Petkova B, et al. Anticancer effect of plant extracts from Lamium album L. by induction of cell death in vitro. Sci Technol. 2012;2(1):55-9.

51. Veleva R, Petkova B, Moskova-Doumanova V, Doumanov J, Dimitrova M, Koleva P, et al. Changes in the functional characteristics of tumor and normal cells after treatment with extracts of white dead-nettle. Biotechnol Biotechnol Equip. 2015;29(1):181-8. doi: 10.1080/13102818.2014.989094.

52. Beuerman RW, Pedroza L. Ultrastructure of the human cornea. Microsc Res Tech. 1996;33(4):320-35. doi: 10.1002/ (sici)1097-0029(19960301)33:4<320::aid-jemt3>3.0.co;2-t.

53. Mohan RR, Possin DE, Mohan RR, Sinha S, Wilson SE. Development of genetically engineered tet HPV16-E6/E7 transduced human corneal epithelial clones having tight regulation of proliferation and normal differentiation. Exp Eye Res. 2003;77(4):395-407.

54. Paduch R, Wozniak A. The Effect of Lamium album Extract on Cultivated Human Corneal Epithelial Cells (10.014 pRSV-T). J Ophthalmic Vis Res. 2015;10(3):229-37. doi: 10.4103/2008-322x.170349.

55. Quade MJ, Roth JA. A rapid, direct assay to measure degranulation of bovine neutrophil primary granules. Vet Immunol Immunopathol. 1997;58(3-4):239-48.

56. Czerwinska ME, Swierczewska A, Wozniak M, Kiss AK. Bioassay-Guided Isolation of Iridoids and Phenylpropanoids from Aerial Parts of Lamium album and Their Anti-inflammatory Activity in Human Neutrophils. Planta Med. 2017;83(12-13):1011-9. doi: 10.1055/s-0043- 
107031.

57. Di Paola R, Esposito E, Mazzon E, Riccardi L, Caminiti $\mathrm{R}$, Dal Toso $\mathrm{R}$, et al. Teupolioside, a phenylpropanoid glycosides of Ajuga reptans, biotechnologically produced by IRBN22 plant cell line, exerts beneficial effects on a rodent model of colitis. Biochem Pharmacol. 2009;77(5):845-57. doi: 10.1016/j.bcp.2008.11.010.

58. Mohseni Mehran SM, Norasfard MR, Abedinzade M, Khanaki K. Lamium album or Urtica dioica? Which is more effective in decreasing serum glucose, lipid and hepatic enzymes in streptozotocin induced diabetic rats: A comparative study. Afr J Tradit Complementary Altern Med. 2015;12(5):84-8. doi: 10.4314/ajtcam.v12i5.13.

59. Mohseni Mehran SM, Norasfard MR, Abedinzade M, Khanaki K. Comparison the effects of Lamium album and Urtica dioica on serum level of glucose and lipid profile in male diabetic rats. Journal of Guilan University of Medical Sciences. 2015;24(93):47-53.

60. Khanaki K, Abedinzade M, Mohammadi M. The Extract of Lamium album and Urtica dioica Increase Serum InsulinLike Growth Factor 1 Level in Streptozotocin-Induced Diabetic Rats. Zahedan Journal of Research in Medical Sciences. 2017;19(12):e58054. doi: 10.5812/zjrms.58054.

61. Wu J, Yan LJ. Streptozotocin-induced type 1 diabetes in rodents as a model for studying mitochondrial mechanisms of diabetic beta cell glucotoxicity. Diabetes Metab Syndr Obes. 2015;8:181-8. doi: 10.2147/dmso.s82272.

62. Bereket A, Lang $\mathrm{CH}$, Blethen SL, Gelato MC, Fan J, Frost RA, et al. Effect of insulin on the insulin-like growth factor system in children with new-onset insulindependent diabetes mellitus. J Clin Endocrinol Metab. 1995;80(4):1312-7. doi: 10.1210/jcem.80.4.7536205.

63. Grant PJ, Stickland MH, Bristow AF, Clarke RF, Wales
JK. Insulin increases plasma somatomedin C (IGF-1) concentrations in adult type 1 diabetic patients. Diabet Med. 1989;6(3):245-8.

64. Khanaki K, Abedinzade M, Gazor R, Norasfard MR, Jafari-Shakib R. Effect of Lamium album on mitochondrial oxidative stress in diabetic rats. Research in Molecular Medicine. 2017;5(2):9-13. doi: 10.29252/rmm.5.2.9.

65. Otles S, Yalcin B. Phenolic compounds analysis of root, stalk, and leaves of nettle. ScientificWorldJournal. 2012;2012:564367. doi: 10.1100/2012/564367.

66. Djelili H, Arrar L, Naline E, Devillier P. Relaxant effects of quercetin and rutin on human isolated bronchus. Chin Med. 2012;3(2):94-100. doi: 10.4236/cm.2012.32015.

67. Aviello G, Scalisi C, Fileccia R, Capasso R, Romano B, Izzo AA, et al. Inhibitory effect of caffeic acid phenethyl ester, a plant-derived polyphenolic compound, on rat intestinal contractility. Eur J Pharmacol. 2010;640(1-3):163-7. doi: 10.1016/j.ejphar.2010.04.040.

68. Arefani S, Mohseni Mehran SM, Moladoust H, Norasfard MR, Ghorbani A, Abedinzade M. Effects of standardized extracts of Lamium album and Urtica dioica on rat tracheal smooth muscle contraction. J Pharmacopuncture. 2018;21(2):70-5. doi: 10.3831/kpi.2018.21.008.

69. Roman I, Puica C, Toma V. The effect of Lamium album and Lamium purpureum extracts on some blood parameters under anakinetic stress conditions in Wistar rats. Bull Univ Agric Sci Vet Med Cluj Napoca. 2016;73(1):18-20. doi: 10.15835/buasvmen-vm:10902.

70. Kumar NA, Tripathi Y, Haleagrahara N, Jeganathan PS, Ramaswamy C, Bolumbu G, et al. Effect of chronic immobilization stress on some selected physiological, biochemical and lipid parameters in Wistar Albino Rats. Res J Pharm Biol Chem Sci. 2012;3(1):34-42. 